\title{
Study on the Commercial Sexual Behavior among Migrants in China
}

$$
\text { Jun-Qing WU }{ }^{1,2, a^{*}} \text {, Yu-Yan LI }{ }^{1,2, b} \text {, Yi-Ran LI }{ }^{1,2, c} \text {, Chuan-Ning YU }{ }^{3, d}
$$

${ }^{1}$ Department of Epidemiology and Social Science on Reproductive Health, Shanghai Institute of Planned Parenthood Research, Fudan University, Shanghai 200237, China

${ }^{2}$ The Key Laboratory of Family Planning Device of National Population and Family Planning Commission, Shanghai 200032, China

${ }^{3}$ School of Public Health, Fudan University, Shanghai, China; No.138yixueyuan Road, 200032; Shanghai, China

a wujq1688@163.com, blyy1033@163.com, cllyyyrr@sina.com, dyu.chuanning64@gmail.com

${ }^{*}$ Corresponding author

Keywords: Migrants, Commercial sexual behavior, Influencing factors

\begin{abstract}
Background: The commercial sexual behaviorual behavior maybe a high risk factor for STD/ HIV spread. To understand the commercial sexual behaviorual behavior and some potential influencing factors among migrants in Shanghai, Beijing, Chongqin, Chengdu, Shanxi and Hanzhou, we conducted this epidemiology survey. Methods: This study was an epidemiological cross-sectional survey that was conducted in Shanghai, Beijing, Chongqin, Chengdu, Shanxi and Hanzhou. During October 2011 to Feb. 2012, quantitative data was collected by the trained investigators using designed questionnaires through face to face anonymous in-depth questionnaire survey. Results: Total 783 migrants were enrolled in this study by multi-phrase sampling in 6 provinces and cities, 704 of whom had sexual behavior. The proportion of subjects who had commercial sexual behaviorual behavior was $4.60 \%$. The results of uni-variate analysis showed that $8.20 \%$ of male subjects and $2.15 \%$ of women had commercial sexual behaviorual behavior. Multi-logistic regression showed that gender, sex partner for the first sexual lives were potential influencing factors of commercial sexual behaviorual behavior. Compared with men, women had lower commercial sexual behavior ( $\mathrm{OR}=0.28,95 \%$ CI: 0.13-0 .63). Those whose first sexual partner were not the spouse had slightly higher commercial sexual behavior $(\mathrm{OR}=2.26$, 95\%CI:0.91-5.65), but the difference was not statistically significant $(\mathrm{P}=0.081)$. Conclusions: The commercial sexual behavior has played the "bridge" role on the spread of $\mathrm{RE}$ TI/STD/HIV/AIDS from high-risk groups to the general population. Male migrants have higher risks of commercial sexual behavior, and those who had a non-spouse sex partners for the first time also had a higher commercial sexual behavior. To advocate safe sex and to reduce commercial sexual behavior, especially for male migrants should be put more emphasis on.
\end{abstract}

\section{Introduction}

With the rapid development of economy in China, more and more people left their hometown and went to big cities. The size of migrant was a great challenge to STI/HIV/AIDS prevention and control. Compared with permanent ones, migrants had their characteristics: a huge amount, mainly from the countryside to the towns, lower economic social status, lower education level, mainly on childbearing and reproductive age. Migrant was chronically deprived of family care, which will badly affect their physical and mental health. Long-term sense of loneliness will lead them separate from the norms of society, resulting in more adverse risk of "non-fixed behavior" than ordinary people. A number of studies have shown that the migrants are at high risk of commercial sexual behavior. Combination of floating and some RTI/STD/HIV/AIDS related high risk behavior would lead to the rapid spread of RTI/STD/HIV/AIDS. In order to explore knowledge, attitude, behavior relevant to Commercial sexual 
behavioral among migrants in Shenzhen city, funded by China AIDS roadmap tactical support project, this study was successfully implemented.

\section{Materials and methods}

\section{Study design and population}

This study was an epidemiological cross-sectional survey that was conducted in Yantian, Luohu, Futian Districts, Shanghai, Beijing, Chongqin, Chengdu, Shanxi and Hanzhou During October 2011 to Feb. 2012

Six provinces and cities were selected for this study. The selected criterions of these provincies and cities include: transient population is concentrated, they had good network of family planning and stable study population, this project was supported by the National Twenveth-five-year's Program and all the leaders and relevant departments were strongly support the implementation of the project. The selected criterions of migrant include: household not in residence, living in the region more than 6 months, aged 15 to 49 years old, informed consent and voluntary participation in this study.

The survey contents mainly include: general demographic characteristics, knowledge on sexually transmitted diseases and HIV/AIDS, attitudes towanrds and status related to commercial sexual behavior and its possible influential factors.

\section{Sample size and statistics}

Total of 783 migrants were recruited by multi-phrase sampling in 6 dweller centers, and information was collected by the trained investigators using the standard questionnaires. There were 130 or 131 migrants for each city for the in-depth interview about their sexuality related issues.

Quantitative data was collected through epidemiological anonymous questionnaire survey. During the whole survey, quality control was implemented according to strict rules from different aspects: questionnaire design, investigator training, on-site, survey review, data entry and so on.

Pair coding, using Epidata3.0 to entry data and proofread, then doing logic check to make sure the data was correct. And the SAS 9.1 software was used to analyze those data. Statistical methods mainly included chi-square test, multi-linear regression, multi-logistic regression, and rank correlation analysis etc.

\section{Results}

Total 783 migrants were enrolled in this study by multi-phrase sampling in 6 provinces and cities, 812 of whom had sex life. Among the subjects, $39.5 \%$ of them were male and $60.5 \%$ were female. $86.79 \%$ of the participants age ranged from 20 to 39 years, and $79.8 \%$ was reported lower educational level (junior or high school). Additionally, $70 \%$ of the participants have lower income, and the recent 3-month average income was less than 2000 RMB. Also, $61.14 \%$ had a rural household, $60.26 \%$ were married. More than $80 \%$ of the participants went out for labor service.

The average age of first marriage among married participants is about $24.21 \pm 2.96$ years. Among the 812 who had sexual life, their first sex age is $21.83 \pm 3.26$ years. The proportion of premarital sex is $49.88 \%$ among participants. The proportion of subjects who had Commercial sexual behavioral was $4.60 \%$. $8.20 \%$ of male subjects and $2.15 \%$ of women had Commercial sexual behavioral.

The results of univariate analysis were as followings. It showed that female subjects who had commercial sexual behavior were less than men $\left(\chi^{2}=15.75 ; \mathrm{P}<0.0001\right)$.

RTI/STD/HIV/AIDS related knowledge ( 5 category 68 items) includes: general knowledge, common symptoms, preventative measures, transmission, partner notifacation, and condom use, including male and female condom. The knowledge score giving principles are as followings: if the answer is right then worth 1 score, wrong or no answer is 0 score. The total score is converted to centesimal system. Other results of univariate analysis were the followings: knowledge score, first sex partner might be influential 
factors of conmercial sexuality. The higher the scores were, the higher the commercial sexual behavior was. Compared with those who didn't have commercial sexual behavior $(56.576 \pm 21.053$ points), subjects with commercial sexual behavior had higher average knowledge scores (63.042 \pm 22.366 points) $(\mathrm{P}=0.065)$. Subjects whose knowledge scores were above 80 points had a higher proportion of commercial sexual behavior $(\mathrm{P}=0.006)$. Compared with those subjects who had first sex behavior with spouse, those having first sex with other people were more likely to report commercial sexual behavior $(\mathrm{P}<0.0001)$ (See Table 2). After adjusting gender, those subjects who had lower knowledge scores were less likely to report Commercial sexual behavioral, and the differences was statistically significant $(\mathrm{P}=0.036)$. Notably, subjects who had different kinds of first sex partners also reported different commercial sexual behavior rate $(\mathrm{P}=0.011)$.

Table 1 Commercial Sexual Behavioral among Different Participants

\begin{tabular}{|c|c|c|c|c|c|}
\hline Variables & $\mathrm{N}$ & Yes & No & $\chi^{2}$ & $\mathrm{P}$ \\
\hline Age group & & & & 0.77 & 0.857 \\
\hline$<20$ & 11 & 0.00 & 100.00 & & \\
\hline $20-$ & 391 & 4.86 & 95.14 & & \\
\hline $30-$ & 306 & 4.25 & 95.75 & & \\
\hline $40-$ & 75 & 5.33 & 94.67 & & \\
\hline Gender & & & & 15.75 & $<0.000$ \\
\hline Male & 317 & 8.20 & 91.80 & & \\
\hline Female & 466 & 2.15 & 97.85 & & \\
\hline Highest level of education & & & & 1.95 & 0.378 \\
\hline Primary school or less & 27 & 3.70 & 96.30 & & \\
\hline Junior or high school & 608 & 4.11 & 95.89 & & \\
\hline College and above & 148 & 6.76 & 93.24 & & \\
\hline Recent 3-month Professional & & & & 4.79 & 0.091 \\
\hline unemployed & 85 & 0.00 & 100.00 & & \\
\hline Service trade & 295 & 4.75 & 95.25 & & \\
\hline others* & 403 & 5.46 & 94.54 & & \\
\hline Recent 3-month income & & & & 5.61 & 0.061 \\
\hline$<1000$ & 196 & 3.06 & 96.94 & & \\
\hline $1000-$ & 354 & 3.67 & 96.33 & & \\
\hline $2000-$ & 233 & 7.30 & 92.70 & & \\
\hline The nature of the account & & & & 2.11 & 0.146 \\
\hline Rural registration & 461 & 3.69 & 96.31 & & \\
\hline Urban account & 322 & 5.90 & 94.10 & & \\
\hline Marital status & & & & 2.81 & 0.094 \\
\hline Married & 554 & 3.79 & 96.21 & & \\
\hline Unmarried & 229 & 6.55 & 93.45 & & \\
\hline
\end{tabular}

Note: *Include: workers, administration staff, technical, military, individual practitioner.

The results of multivariate logistic analysis about commercial sexual behavior were as follows. In multivariate models, we incorporated gender, educational level, occupation, knowledge scores, age of first sex and first sex partner as independent variable into stepwise logistical regression models predicting either active or passive factors. Gender was the main predictor of having commercial sexual behavior. Compared with men, women were less likely to report commercial sexual behavior $\mathrm{OR}=0.28$, $\mathrm{P}=0.002$ ). Compared with those subjects who had first sex behavior with spouse, those having first sex 
with other people were more likely to report commercial sexual behavior. However, the difference was not statistically significant $(\mathrm{P}=0.081)$ (See Table 3).

Table 2 Possible Factors Associated with Commercial Sexual Behavior

\begin{tabular}{lcccccc}
\hline Variable & $\mathrm{N}$ & Yes & No & $\chi^{2}$ & $\mathrm{P}$ & $\mathrm{P}^{*}$ \\
\hline Scores & & & & 12.46 & 0.006 & 0.036 \\
$\quad<60$ & 353 & 3.12 & 96.88 & & & \\
$\quad 60-$ & 176 & 5.68 & 94.32 & & & \\
$\quad 70-$ & 152 & 2.63 & 97.37 & & & \\
$\quad 80-$ & 102 & 10.78 & 89.22 & & & \\
First sex partner & & & & 17.02 & 0.000 & 0.011 \\
$\quad$ Lover & 439 & 5.47 & 94.53 & & & \\
$\quad$ Spouse & 294 & 2.04 & 97.96 & & & \\
$\quad$ Temporary sex partner & 27 & 18.52 & 81.48 & & & \\
\hline
\end{tabular}

Note: $\mathrm{P}^{*}$ meant $\mathrm{P}$ value after adjusting gender

Table 3 Results of Multiple Logistic Regression Models for Commercial Sexual Behavior

\begin{tabular}{lllllll}
\hline Variable & Compare G & Control G & OR & \multicolumn{2}{c}{$95 \% \mathrm{CI}$} & $\mathrm{P}$ \\
\hline gender & female & male & 0.28 & 0.13 & 0.63 & 0.002 \\
score & $\geq 60$ & $<60$ & 1.69 & 0.79 & 3.62 & 0.179 \\
First sex partner & Non-spouse & Spouse & 2.26 & 0.91 & 5.65 & 0.081 \\
\hline
\end{tabular}

\section{Discussions}

We defined "commercial sexual behavior" as exchanging sex or sexual acts for items such as money or property. The proportion of subjects who had Commercial sexual behavioral was $4.60 \%$. 8.20\% of male subjects had commercial sexual behavior, $2.15 \%$ of women had ones. Based on a study about migrants in Shanghai, Beijing, Chongqin, Chengdu, Shanxi and Hanzhou City by Cai Wen-de [3], the rate of commercial sexual behavior was $6.0 \%$. Similar rates of commercial sexual behavior have been found among migrants in Beijing by Lin Xiu-yun [4]: 9.4\% of the subjects had commercial sexual behavior, and only $39.0 \%$ used condoms during commercial sexual behavior. Another study showed that $9.9 \%$ of the migrant in Nanjing and Beijing had commercial sexual behavior partners in a month, only $18 \%$ of the respondents reported often or always used condoms, $20 \%$ respondents used sometimes or occasionally [5].

Because commercial sexual behavior is a kind of exchanging sex for money or property, the sexual partner was usually a commercial sexual behavior worker. Generally, commercial sexual behavior is considered as unsafe sex, our data is self-reported; therefore participants may under-report those behaviors that are illegal or stigmatizing. We have attempted to minimize this limitation through repeated assurances of confidentiality and through establishment of rapport between participant and interviewer over time.

At present, most previous research has been focused on STD / AIDS knowledge and condom use or infection status about commercial sexual behavior respondents. Little is known about the influential factors of commercial sexual behavior, especially among migrants. Therefore, previous findings may not be directly comparable to the current study.

The study was community-based, and quantitative data was collected front to front by multi-phrase sampling on the migrants in 6 provinces and cities of Shanghai, Beijing, Chongqin, Chengdu, Shanxi and Hanzhou City. It made a comparative analysis on the demographic characteristics and some related 
indicators of those respondents who had commercial sexual behavior and those not. Additionally, we used a multivariate logistic analysis approach to explore the factors that were associated to commercial sexual behavior.

In this study, we found that compared with men, women had lower commercial sexual behavior. This was the same as reported by previous studies of Wu Junqing from "Call of HIV/STDs patients in China". What's more, the finding was further verified in multi-factors logistic model. However, it showed there was statistically significant difference among those who had different knowledge scores. From the perspective of this study, among those who had commercial sexual behavior, $10.78 \%$ having knowledge scores over 80 points, the proportion was higher than that of the low-scoring participants (P $=0.036$ ). But this was not verified in multi-factors model. This result might be due to that after the participants had commercial sexual behavior, high-risk behavior, they went to learn more about RTI/STD/HIV/AIDS related knowledge. First sex partner is an important indicator, which reflects the sexual attitudes, sexual ethics and so on, also has a significant impact on the formation of their patterns of sexual behavior. The chi-square analysis showed that a non-spouse object for the first sex had slightly higher commercial sexual behavior, but in multi-factors analysis, the difference was not statistically significant $(\mathrm{OR}=2.26,95 \% \mathrm{CI}$ : 0.91-5 .65). This might be due to the small sample size of those who had commercial sexual behavior $(n=35)$. But it indicated that a larger sample size of study should be done to further verify the possible effects.

Migrant is emerging as an important social group in our society. Such a large movement of groups has not only brought great influence on the city's development, but also made a great contribution to rural development as well as the national economic development. Some studies [4] show that the migrant and their susceptibility has something to do with their mobility, a sense of loneliness, sexual morality, poor knowledge, reproductive health behavior.

Due to various reasons, migrant cannot truly integrate into urban life, and accordingly, government departments are ignored to provide some information about reproductive health, safe sex, the right promotion and management of the concept of marriage and child bearing, even unwilling to cooperate with the local government sector work. The commercial sexual behavior has played the "bridge" role on the spread of RTI/STD/HIV/AIDS from high-risk groups to the general population. A substantial research has shown that migrant is high risk group. To advocate safe sex and the correct concept of marriage and reduce commercial sexual behavior, especially male migrants should be put more emphasis on[9]. Therefore, appropriate and comprehensive IEC about sexual and reproductive health and RTI/STD/HIV/AIDS should be taken, such as safe sexual behavior, correct concept of marriage and child bearing, and so on.

Meanwhile, in connect with the migrant's different cultures, occupations, working background, different strategies should be taken. What's more, promoting the condoms use in preventing RTI/STD/HIV/AIDS may be helpful for the prevention and control of RTI/STD/HIV/AIDS through sexual transmission [10].

The migrant's reproductive health issue is related to China's economic and social development. Safeguarding migrant's access to the legitimate rights and interests of reproductive health, meeting their needs of RTI/STD/HIV/AIDS treatment and prevention, is an important part of building a harmonious society.

\section{Acknowledgment}

Thanks for the financial support from the National 12th Five-Year's Plan (No.2012BAI32B08).

\section{References}

[1]Shenzhen Municipal Statistics Bureau of Statistics data. http://www.sztj.com/main/xxgk/tjsj/tjgb/gmjjhshfzgb/200903243520.shtml (2008) 
[2] National Bureau of Statistics of China.Statistics of the sixth national census in 2012.Accessed 18 January 2012 from:http://www.ce.cn/macro/more/201201/18/t20120118_23009813.shtml(2012)

[3] Cai Wende, Tan Jingguang, LUO Xian-ru. Survey on AIDS-related knowledge and behaviors among migrant in Shenzhen City. Public Health and Preventive Medicine, 17 (2006) 103-104

[4] Vaidya NK, Wu J. HIV epidemic in Far-Western Nepal: effect of seasonal labor migration to India. BMC Public Health,11(2011) 310

[5] Zhou H, Wang XY, Ye F, Gu HH, Zeng XP. Contraceptive knowledge, attitudes and behavior about sexuality among college students in Beijing, China. Chin Med J (Engl) 125(2012) 1153-1157

[6] Jun-qing Wu, Liu-bin Yi, Wen-ying Li, Zong-Min Jiang. knowledge level about HIVAIDS among reproductive men in five counties in China. Journal of Reproduction and Contraception,18(2007) $121-126$

[7] Tenkorang EY, Maticka-Tyndale E, Rajulton F. A multi-level analysis of risk perception, poverty and sexual risk-taking among young people in Cape Town, South Africa. HEALTH \& PLACE, 17 (2011) 525-535

[8] Kim Yuelong, Yao Yingshui, He Jiangang. Analysis on AIDS-related knowledge, behavior and condom use among commercial sexual behavior workers. Chinese Health Service Management, (2009) 61-62

[9] Zhuang X, Wu Z, Poundstone K, Yang C, Zhong Y. HIV-related high-risk behaviors among Chinese migrant construction laborers in Nantong, Jiangsu. PLoS One,7 (2012) e31986

[10] Jun-Qing Wu, Yu-Yan Li, Jing-Chao Ren, Na Li, Yin Zhou, Rui Zhao, Yu-Feng Zhang. Male condom use and condom problems among women in Shanghai. Asian Pacific Journal of Reproduction,1(2012) 48-54 